\title{
Multicriteria analysis for the choice of an intervention strategy for historic monuments-case of the enclosure of the medina of Salé-
}

\author{
Driss Elhachmi ${ }^{1, *}$, Lahcen Bahi ${ }^{1}$,Latifa Ouadif $^{1}$, and Rachid Benkmil ${ }^{1}$ \\ ${ }^{1}$ L3GIE Laboratory, Mohammadia Engineering School, Mohammed V University in Rabat-Morocco
}

\begin{abstract}
Historical monuments in Morocco represent a heritage, of great value in terms of its history, culture, civilization and identity. This heritage is a non-renewable resource considered as one of the essential aspects of modern communities and contributes to the sustainable development of the country. Unfortunately, these monuments are subject to pathologies due to several factors that threaten its sustainability. The choice of the type of intervention thus becomes a strategic decision that has a crucial impact on the historic monument. Indeed, it requires a global approach because it involves simultaneously a multitude of stakeholders and a multitude of criteria (technical, environmental, social, political or administrative, human etc ...). Several models in the literature have focused on the multi-criteria decision support process. This work proposes a decision support method based on the Analytic Hierarchy Process (AHP) method, in order to apply it to a choice of an intervention strategy on historic monuments. Then, this approach is applied to the case of the enclosure of the old medina of Salé.
\end{abstract}

\section{Introduction}

Historic monuments are a heritage, a lever for the country's sustainable development and a non-renewable resource. Unfortunately, these monuments have been devalued to the detriment of urban development, and suffer several degradations. Their development requires today a major effort of the public power.

Intervention on historic monuments thus becomes a complex decision-making problem. It has a crucial impact on the sustainability of these monuments. The various interventions in the past have generated impacts and failures that have compromised the stability of the monuments in place[1,2,3]. The intervention must respect three fundamental principles: authenticity, minimal intervention and reversibility [4]. These principles must take into account the choice of materials, techniques and solutions to be adopted [5].

Before any intervention, it is necessary to seek compatible solutions in order to avoid interventions that negatively affect the particularities of the monuments [6].

Intervention on historic buildings is a multi-criteria decision-making problem. It must take into account the analysis of several dimensions, such as historical and artistic value, economic constraints, environmental impacts, etc. [7]. It also involves the decisions of several actors with different objectives and intentions (government representatives, architects, historians, developers) [8].
In view of this situation, and to better guide decisionmakers in their choice, a multi-criteria analysis using the AHP method can be used [9].

The method (AHP), developed by Saaty, is an effective process for dealing with complex decision problems [10]. It is a useful and powerful tool that implies quantitative, qualitative criteria such as subjective judgments and multiple objectives [11].

The parametrization of this method is controlled by a consistency ratio without overriding the subjectivity of an expert's choices, thus influencing the solution proposed by this method.

The purpose of this work is to develop a methodology for intervening on the historical monuments of the enclosure of the Old Medina of Salé using the AHP method.

\section{AHP method}

Developed by Thomas SAATY in 1980, AHP (Analytic Hierarchy Process) is a simple and effective decision support method for dealing with complex problems with multiple attributes [10]. It is a flexible and simple technique, frequently used by researchers and practitioners to compare several objectives or alternatives [12]. It makes it possible to establish ranking relationships between alternatives through pairwise comparisons [10].

The AHP method integrates all qualitative and quantitative criteria into its hierarchical structure, it also takes into account the opinion and assessment of decision-makers[13]. The AHP process allows a

\footnotetext{
Corresponding author: hachmi80@gmail.com
} 
complex problem to be divided into small parts, to help decision-makers assess preferences [14].
The following chart shows the steps followed to apply the AHP process in our case study, fig.1.

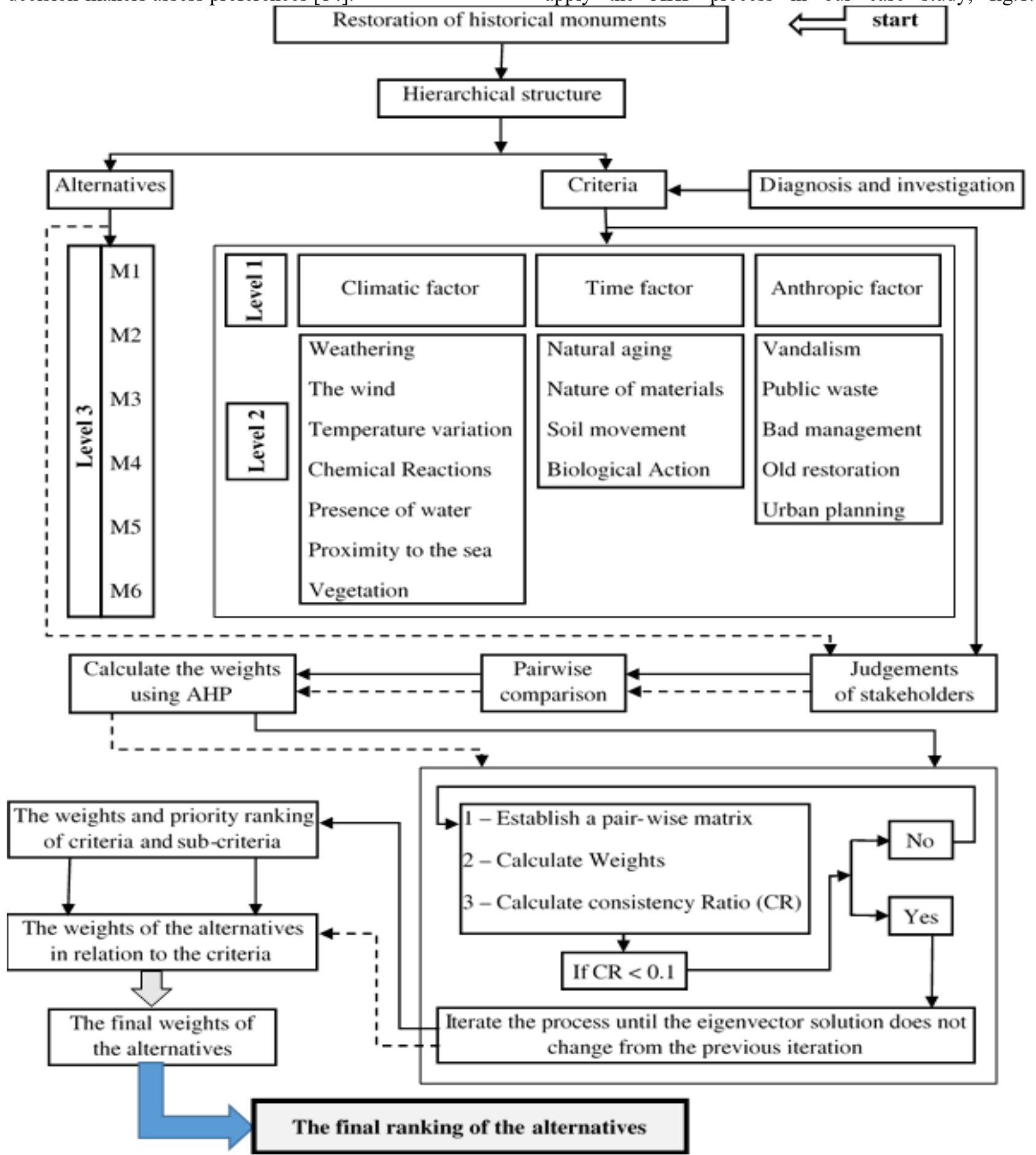

Fig.1. The flow chart illustrating the methodology used to evaluate the criteria, sub-criteria and alternatives.

\section{Case study}

\subsection{Description of the case study}

The old Medina of Salé, is an 11th century medieval city, characterized by its enclosure as Islamic defensive works. This enclosure is classified as a historical monument with all its components.

Geographically, it is located on the northern shore of the OuedBouregreg and on the Atlantic Ocean on the western side. Its climate is sub-humid Mediterranean (according to Emberger-Sauvage classification).

This region of Rabat SaléKenitra is characterized by an annual rainfall of $600 \mathrm{~mm}$, the relative average monthly humidity between $50.96 \%$ and $92.4 \%$ and the average monthly temperature varies between $13{ }^{\circ} \mathrm{C}$ and $23^{\circ} \mathrm{C}$ (Source Meteorology Department of Morocco).

In addition to the ramparts, the enclosure of the medina of Salé includes several buildings classified as 
historical monuments such as: bastions (Bordj) and doors (Bab).

In this case study, it concerns the application of the AHP method to the restoration of historic monuments located on the enclosure of the medina of Salé.

\subsection{Identification of alternatives and criteria}

In order to establish an intervention strategy on the enclosure of the medina of Salé, we carried out a diagnosis of the historical monuments located on this site. Then we identified alternatives to the decision by excluding the historical monuments already restored, the others that have been demolished or transformed.

As part of this screening study, we identified six (6) historic monuments located on this site.

The location of these alternatives is shown on the map of the city, fig.2. Their names are :BordjAddoumoue (M1), Sqalla (M2), BordjArrokni (M3),BordjLamtemmen (M4), Bab Lamrissa (M5) and Bab Dar Assinaa (M6). The photos of these monuments are shown in Fig.3.

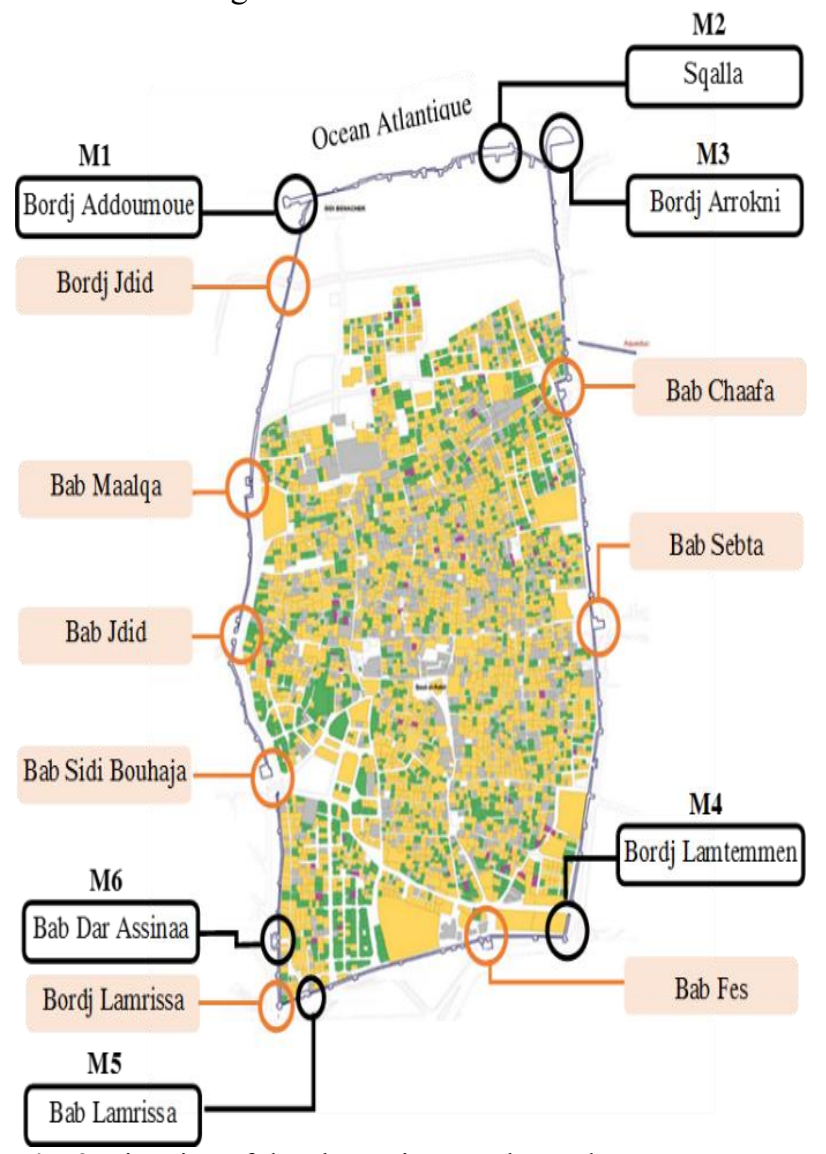

Fig. 2. Situation of the alternatives on the enclosure.

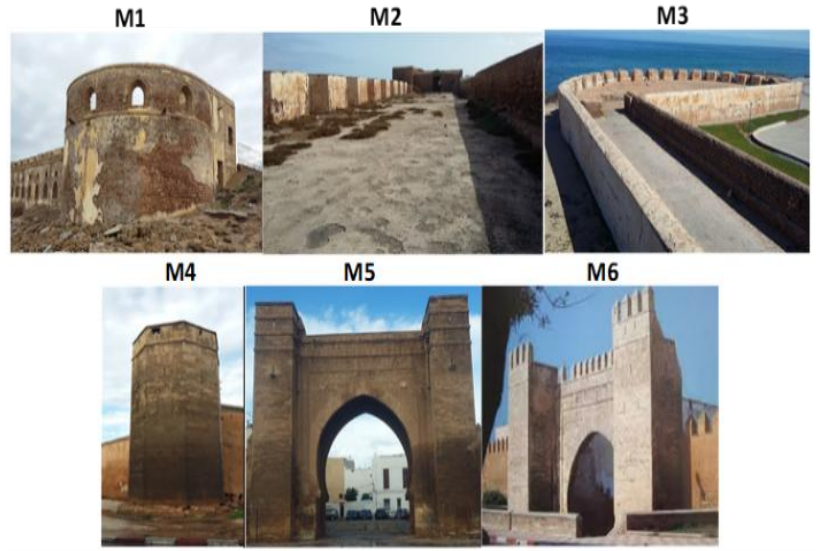

Fig. 3. Images of the alternatives on the Salé enclosure.

The intervention on these historic monuments takes into account the criteria or degradation factors that influence the overall objective of this intervention.

In our case study, we are interested in classifying the list of alternatives according to a list of criteria. The main criteria taken into account: Climate (CL), Time (T) and the anthropic criterion (AN). These criteria include several sub-criteria that are listed in Table 1.

Table 1.Main criteria and sub-criteria.

\begin{tabular}{|c|l|c|l|}
\hline \multicolumn{5}{|c|}{ MainCriteria and sub-criteria } \\
\hline \multicolumn{3}{|c|}{ CL - Climatic } \\
\hline WE & Weathering & PRW & Presence of water \\
\hline WI & The Wind & PS & Proximity to the sea \\
\hline TV & Temperature variation & VG & Vegetation \\
\hline CR & Chemical Reactions & & \\
\hline \multicolumn{4}{|c|}{ T - Time } \\
\hline NA & Natural aging AN - Anthropic \\
\hline NM & Nature of materials & BA & Biological Action \\
\hline \multicolumn{5}{|c|}{ AN } & Soilmovement \\
\hline VA & Vandalism & OR & Old restoration \\
\hline PW & Public waste & UP & Urban planning \\
\hline BM & Bad management & & \\
\hline
\end{tabular}

In this work we will study the effect of these main criteria and the sub-criteria on the different alternatives and establish restoration priorities for a better intervention strategy on these monuments.

\subsection{Hierarchical structure of the problem}

The AHP method makes it possible to represent the elements of the problem in a hierarchical structure and to evaluate the alternative solutions that best suit the objectives [15]. Indeed, the decomposition will be carried out in several levels: the objective in level 0 , the criteria in level 1 and sub criteria in level 2, and the alternatives in level 3 see fig. 4 . 


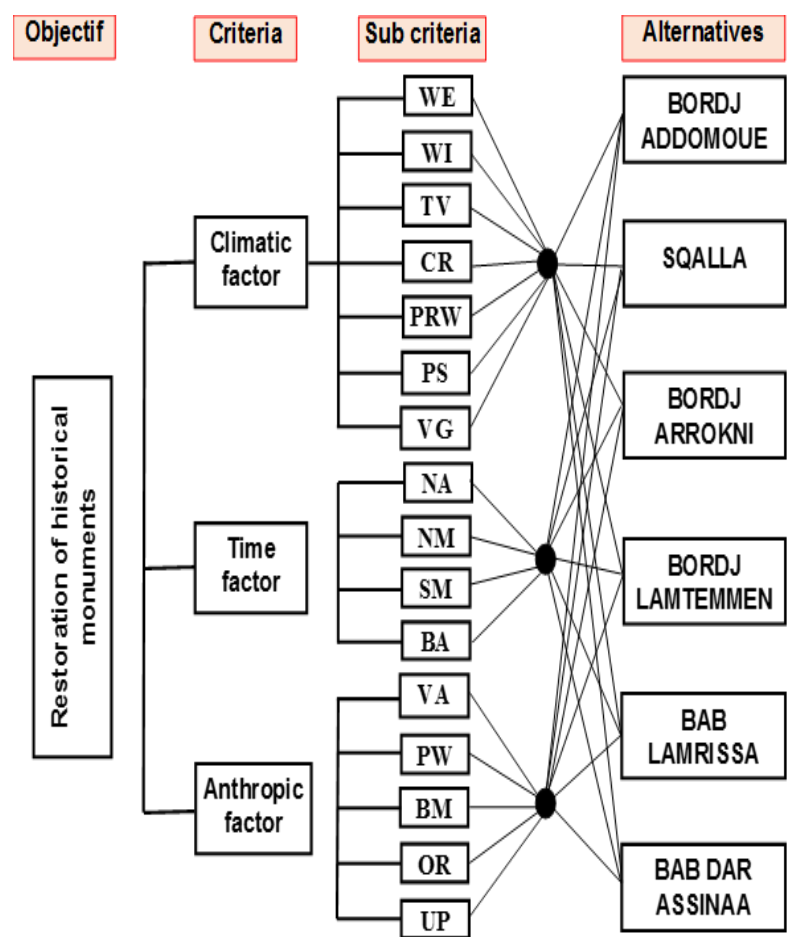

Fig.4. hierarchical structure of the problem.

\subsection{Results and discussion}

Once the hierarchy of the problem has been established, the elements of this hierarchy can be compared in pairs.

By consideringthe judgements of stakeholders (decision-makers, experts, local authorities, researchers and local populations), the relative importance of the different elements of the problem hierarchy can be assessed. This evaluation is established by the AHP method using the Saaty binary comparison scale "1-9", which allows the construction of judgment matrices.

There may be inconsistencies in judgment when creating these matrices. A consistency test is carried out to reduce the subjectivity of the judgment and ensure the rationality of the weights.

\subsubsection{Evaluation of criteria and sub-criteria}

The results of the pairwise comparison of the criteria and sub-criteria are presented in Tables 2, 3, 4 and 5.

Table 2. Matrix for pairwise comparison of the main criteria Climate (Cl), Time (T), Anthropic (AN).

\begin{tabular}{|c|c|c|c|c|c|}
\hline Criteria & Climatic & Time & \multicolumn{2}{|c|}{ Anthropic } & Weight \\
\hline Climatic & 1 & $1 / 5$ & \multicolumn{2}{|c|}{$1 / 7$} & 0,074 \\
\hline Time & 5 & 1 & \multicolumn{2}{|c|}{$1 / 3$} & 0,283 \\
\hline Anthropic & 7 & 3 & \multicolumn{2}{|c|}{1} & 0,643 \\
\hline$\lambda \max =$ & 3,066 & $\mathbf{C I}=$ & 0,033 & $\mathbf{C R}=$ & 0,056 \\
\hline
\end{tabular}

According to Table 2 , the $\mathrm{CR}$ consistency ratio obtained for the evaluation of the main criteria is 0.056 .
This ratio is less than 0.10 , indicating an acceptable level of consistency.

It follows from Table 2 that the most important criterion influencing these historic monuments is the anthropic criterion. It has a weight of 0,643 followed by the time criterionwith a weight of 0,283 and then the climatic criterion which is the least important with a weight of 0,074 .

Table 3. Matrix for pairwise comparison of climatic subcriteria, Weather (WE), wind (WI), temperature variation (TV), chemical reactions (CR), presence of water (PRW), proximity to the sea (PS), vegetation (VG).

\begin{tabular}{|c|c|c|c|c|c|c|c|c|}
\hline $\begin{array}{c}\text { Subcriteri } \\
\text { a } \\
\end{array}$ & $\begin{array}{l}\mathbf{W} \\
\mathbf{E} \\
\end{array}$ & $\begin{array}{l}\text { W } \\
\text { I }\end{array}$ & $\begin{array}{l}T \\
\mathrm{~V} \\
\end{array}$ & $\begin{array}{l}\mathbf{C} \\
\mathbf{R} \\
\end{array}$ & $\begin{array}{l}\text { PR } \\
\text { W }\end{array}$ & PS & $\begin{array}{l}\mathbf{V} \\
\mathbf{G} \\
\end{array}$ & $\begin{array}{c}\text { Weigh } \\
\mathrm{t}\end{array}$ \\
\hline WE & 1 & 9 & 9 & $1 / 7$ & $1 / 3$ & 1/ & 2 & 0,129 \\
\hline WI & $1 / 9$ & 1 & 1 & $1 / 7$ & $1 / 7$ & $\begin{array}{l}1 / \\
6\end{array}$ & $1 / 3$ & $\mathbf{0 , 0 2 8}$ \\
\hline TV & $1 / 9$ & 1 & 1 & $1 / 7$ & $1 / 9$ & $\begin{array}{c}1 / \\
7\end{array}$ & $1 / 3$ & $\mathbf{0 , 0 2 6}$ \\
\hline CR & 7 & 7 & 7 & 1 & $1 / 3$ & 1 & 5 & 0,236 \\
\hline PRW & 3 & 7 & 9 & 3 & 1 & 2 & 5 & $\mathbf{0 , 3 2 1}$ \\
\hline PS & 3 & 6 & 7 & 1 & $1 / 2$ & 1 & 5 & 0,202 \\
\hline VG & $1 / 2$ & 3 & 3 & $1 / 5$ & $1 / 5$ & $\begin{array}{l}1 / \\
5\end{array}$ & 1 & $\mathbf{0 , 0 5 9}$ \\
\hline \multicolumn{3}{|c|}{$\lambda \max =7,722$} & \multicolumn{3}{|c|}{$\mathrm{CI}=\mathbf{0 , 1 2 0}$} & \multicolumn{3}{|c|}{$\mathrm{CR}=0,091$} \\
\hline
\end{tabular}

Table 4.Matrix for pairwise comparison of the sub-criteria of Time, Natural ageing (NA), Nature of materials (NM), Soil movement (SM), Biological action (BA).

\begin{tabular}{|c|c|c|c|c|c|}
\hline Subcriteria & NA & NM & SM & $\mathbf{B A}$ & Weight \\
\hline NA & 1 & $1 / 5$ & $1 / 3$ & 1 & 0,102 \\
\hline NM & 5 & 1 & $1 / 2$ & 5 & 0,364 \\
\hline SM & 3 & 2 & 1 & 5 & 0,449 \\
\hline BA & 1 & $1 / 5$ & $1 / 5$ & 1 & 0,085 \\
\hline \multicolumn{2}{|c|}{$\lambda \max =4,140$} & \multicolumn{2}{|c|}{$\mathrm{CI}=\mathbf{0 , 0 4 7}$} & \multicolumn{2}{|c|}{$\mathrm{CR}=\mathbf{0 , 0 5 2}$} \\
\hline
\end{tabular}

Table 5.Matrix for pairwise comparison of the sub-criteria of Anthropic, Vandalism (VA), Public Waste (PW), Bad Management (BM), Old Restoration (OR), Urban planning (UP).

\begin{tabular}{|c|c|c|c|c|c|c|}
\hline $\begin{array}{c}\text { Subcri } \\
\text { teria }\end{array}$ & VA & PW & BM & OR & UP & Weight \\
\hline VA & 1 & 5 & $1 / 3$ & $1 / 2$ & $1 / 2$ & 0,139 \\
\hline PW & $1 / 5$ & 1 & $1 / 7$ & $1 / 5$ & $1 / 4$ & 0,043 \\
\hline BM & 3 & 7 & 1 & $1 / 3$ & 3 & 0,284 \\
\hline OR & 2 & 5 & 3 & 1 & 3 & 0,381 \\
\hline UP & 2 & 4 & $1 / 3$ & $1 / 3$ & 1 & 0,153 \\
\hline \multicolumn{2}{|c|}{$\lambda \max =5,324$} & \multicolumn{2}{|c|}{$C I=0,081$} & \multicolumn{3}{|c|}{$\mathrm{CR}=\mathbf{0 , 0 7 2}$} \\
\hline
\end{tabular}

From Tables 3, 4 and 5, the CR obtained for the evaluation of these sub-criteria is 0,091, 0,052 and 0,072 respectively. Consistency ratios are less than 0.10 , indicating a reasonable level of consistency. 
Based on the results of the pair-wise comparison tables 2, 3, 4 and 5, we calculate the weights of the sub-criteria in relation to the criteria, see table 6 .

Table 6.Final results of pairwise comparison of criteria and sub-criteria.

\begin{tabular}{|c|c|c|c|c|}
\hline \multicolumn{2}{|c|}{ Criteria } & \multicolumn{2}{|c|}{ Sub-criteria } & \multirow{2}{*}{$\begin{array}{c}\text { Final } \\
\text { weight }\end{array}$} \\
\hline Description & Weight & Description & Weight & \\
\hline \multirow{7}{*}{ Climatic } & \multirow{7}{*}{0,074} & WE & 0,129 & $\mathbf{0 , 0 1 0}$ \\
\hline & & WI & 0,028 & $\mathbf{0 , 0 0 2}$ \\
\hline & & TV & 0,026 & $\mathbf{0 , 0 0 2}$ \\
\hline & & $\mathbf{C R}$ & 0,236 & $\mathbf{0 , 0 1 7}$ \\
\hline & & PRW & $\mathbf{0 , 3 2 1}$ & $\mathbf{0 , 0 2 4}$ \\
\hline & & PS & 0,202 & 0,015 \\
\hline & & VG & 0,059 & $\mathbf{0 , 0 0 4}$ \\
\hline \multirow{4}{*}{ Time } & \multirow{4}{*}{0,283} & NA & 0,102 & $\mathbf{0 , 0 2 9}$ \\
\hline & & NM & 0,364 & $\mathbf{0 , 1 0 3}$ \\
\hline & & SM & 0,449 & $\mathbf{0 , 1 2 7}$ \\
\hline & & BA & 0,085 & $\mathbf{0 , 0 2 4}$ \\
\hline \multirow{5}{*}{ Anthropic } & \multirow{5}{*}{0,643} & VA & $\mathbf{0 , 1 3 9}$ & $\mathbf{0 , 0 8 9}$ \\
\hline & & PW & $\mathbf{0 , 0 4 3}$ & $\mathbf{0 , 0 2 8}$ \\
\hline & & BM & 0,284 & $\mathbf{0 , 1 8 3}$ \\
\hline & & OR & $\mathbf{0 , 3 8 1}$ & 0,245 \\
\hline & & $\mathbf{U P}$ & $\mathbf{0 , 1 5 3}$ & $\mathbf{0 , 0 9 8}$ \\
\hline
\end{tabular}

At the level of sub-criteria we distinguish from Table 6 that the old restorations (OR) are the main cause of the deterioration of these historic monuments with a weight of 0.245 followed by the problem of bad management (BM) with a weight of 0.183 and all the climate sub-criteria are the least important with a weight ranging from 0.002 to 0.024 . Indeed, successive restorations, if not well studied, have a negative influence on historical monuments.

It follows from this assessment that, despite the ageing of historic monuments, they can still withstand climatic conditions if they are well restored and managed.

\subsubsection{Evaluation of alternatives}

Taking into account the results of the comparison of the criteria. We evaluated the six historic monuments and calculated their weights for each criterion using the AHP decision-making method. The results of this evaluation are presented in Table 7.

Table 7.Matrix for pairwise comparison of alternatives in relation to the main criteria.

\begin{tabular}{|c|c|c|c|c|c|c|c|c|c|}
\hline Criteria & Monuments & M1 & M2 & M3 & M4 & M5 & M6 & Weight & CR \\
\hline \multirow{6}{*}{ Climatic } & M1 & 1 & $1 / 2$ & $1 / 2$ & 5 & 4 & 7 & 0,211 & \multirow{6}{*}{0,071} \\
\hline & M2 & 2 & 1 & 2 & 5 & 4 & 7 & 0,334 & \\
\hline & M3 & 2 & $1 / 2$ & 1 & 5 & 4 & 7 & 0,261 & \\
\hline & M4 & $1 / 5$ & $1 / 5$ & $1 / 5$ & 1 & $1 / 5$ & 2 & 0,049 & \\
\hline & M5 & $1 / 4$ & $1 / 4$ & $1 / 4$ & 5 & 1 & 5 & 0,114 & \\
\hline & M6 & $1 / 7$ & $1 / 7$ & $1 / 7$ & $1 / 2$ & $1 / 5$ & 1 & 0,031 & \\
\hline \multirow{6}{*}{ Time } & M1 & 1 & 2 & 2 & 5 & 4 & 5 & 0,324 & \multirow{6}{*}{0,088} \\
\hline & M2 & $1 / 2$ & 1 & 2 & 5 & 4 & 7 & 0,265 & \\
\hline & M3 & $1 / 2$ & $1 / 2$ & 1 & 5 & 4 & 7 & 0,215 & \\
\hline & M4 & $1 / 5$ & $1 / 5$ & $1 / 5$ & 1 & $1 / 5$ & 3 & 0,056 & \\
\hline & M5 & $1 / 4$ & $1 / 4$ & $1 / 4$ & 5 & 1 & 3 & 0,104 & \\
\hline & M6 & $1 / 5$ & $1 / 7$ & $1 / 7$ & $1 / 3$ & $1 / 3$ & 1 & 0,036 & \\
\hline \multirow{6}{*}{ Anthropic } & M1 & 1 & $1 / 3$ & $1 / 3$ & 3 & 3 & 5 & 0,177 & \multirow{6}{*}{0,060} \\
\hline & M2 & 3 & 1 & 1 & 3 & 4 & 5 & 0,303 & \\
\hline & M3 & 3 & 1 & 1 & 3 & 4 & 5 & 0,303 & \\
\hline & M4 & $1 / 3$ & $1 / 3$ & $1 / 3$ & 1 & $1 / 2$ & 2 & 0,079 & \\
\hline & M5 & $1 / 3$ & $1 / 4$ & $1 / 4$ & 2 & 1 & 2 & 0,090 & \\
\hline & M6 & $1 / 5$ & $1 / 5$ & $1 / 5$ & $1 / 2$ & $1 / 2$ & 1 & 0,047 & \\
\hline
\end{tabular}

The results in Table 7 show that for the climate criterion, the monument most vulnerable to climatic conditions is the monument $\mathrm{M} 2$ with a weight of 0.334 followed by the M3 with a weight of 0.261 then M1 with a weight of 0.211 and the M5 with a weight of 0.114 . For the time criterion, monuments M1, M2, M3 and M5 have weights of $0.324,0.265,0.215$ and 0.104 respectively. For the anthropic criterion, monuments M2 and M3 are the most affected by the human interventions with a weight of 0.303 followed by monuments M1 with a weight of 0.177 and M5 with a weight of 0.090. Monument M6 is the least vulnerable to all these criteria.

Based on the results in Table 7, the weights of these historic monuments are calculated and prioritized according to Table 8 .

Table 8. Weight of alternatives in relation to the criteria.

\begin{tabular}{|c|c|c|c|c|}
\cline { 2 - 5 } \multicolumn{1}{c|}{} & Climatic & Time & Anthropic & Criteria \\
\cline { 2 - 5 } \multicolumn{1}{c|}{} & 0,074 & 0,283 & 0,643 & Weight \\
\hline M1 & 0,016 & 0,092 & 0,114 & 0,221 \\
\hline M2 & 0,025 & 0,075 & 0,195 & 0,295 \\
\hline M3 & 0,019 & 0,061 & 0,195 & 0,275 \\
\hline M4 & 0,004 & 0,016 & 0,051 & 0,070 \\
\hline M5 & 0,008 & 0,029 & 0,058 & 0,096 \\
\hline M6 & 0,002 & 0,010 & 0,030 & 0,043 \\
\hline
\end{tabular}

According to the results of Table 8 , the monument M2 may be considered the priority for any restoration intervention followed by monument M3 then M1. The other monuments have a weight of 0.295 for M2 and 0.275 for M3 and 0.221 for M1. Monuments M5 and M4 and M6 have respective weights of $0.096,0.070$ and 0.043 . 


\section{Conclusion}

The AHP method allowed us to select the monuments to be restored, and to prioritize them according to the different criteria and sub-criteria. This analysis has allowed us to integrate the judgments of all stakeholders in the restoration of historic monuments.

It follows from this study that the anthropic factor affects the stability and durability of historic monuments more than climatic factors or time. The choice of successive interventions was responsible for this deterioration. Indeed, interventions that are not well studied can have a negative impact on historic monuments and can endanger their structures. The effects of these interventions can only be detected in a subordinate way. Moreover, the absence of a regular care and maintenance programme does not help to preserve the original structures of these monuments to a higher degree.

As a result of this study, restoration interventions are urgently needed to preserve the two historic monuments Sqalla and BorjArrokni. Later on, the BorjAdoumoue monument can be restored. Interventions on other historic monuments can be started in the following order of priority: Bab Mrissa, BorjMtemen and $\mathrm{Bab}$ darAssinaa. This restoration must be based on a detailed analysis of the structure and knowledge of the characteristics of the materials and their behavior. It must take into account the inventory of old interventions and seek compatible techniques and solutions so as not to negatively affect the particularities of these monuments. It is essential to set up a care and maintenance programme with regular monitoring of the condition of these monuments.

\section{References}

1. I. Vidovszky, Procedia Eng, 164, 575-582 (2016).

2. B. Yilmaza, S. Saricam, F. Aslan, A. Atik, JEPE, 15, 3, 1181-1190 (2014).

3. D. Popa, D. M. Popa, JEPE, 17, 4, 1345-1350 (2016).

4. ICOMOS, charter of venice (1964).

5. R. Benkmil, L. Bahi, A. Aakhssass, L. Ouadif, IJCIET, 9, 4, 1680-1688, (2018).

6. J.A. Fernandez-Nicolas, M. Jimenez-Espada, IOP Conf. Ser.: Mater. Sci. Eng, 471, 1-10 (2019).

7. M. Mazzanti, JSE, 31, 5, 529-558 (2002).

8. V. Ferretti, M. Bottero, G. Mondini, JCH, 15, 644655 (2014).

9. S. Ben Mena, BASE, 4, 2, 83-93 (2000).

10. I. Sbeity, M. Dbouk, H. Kobeissi, IJSEA, 5, 4, 3950 (2014)

11. H. Altay Guvenir, E. Erel, EJOR, 105, 29-37 (1998)

12. A. Ait Errouhi, L. Bahi, L. Ouadif, A. Akhssas, Y. Bouroumine, A. Bahi, MATEC Web Conf, 149, 1-7 (2018).
13. T. Saaty, MATH COMPUT MODEL, 46, 860891, (2007).

14. D. Elhamdouni, A. Arioua, A. Elhmaidi, JMES, 8, 10, 3612-3624 (2017).

15. B. Kaoutar, B. Lahcen, IJERA, 2,6,16761684(2012). 